\section{Rendimiento de dos índices predictores de mortalidad (PSI y CURB-65) en pacientes adultos inmunocompetentes hospitalizados por neumonía adquirida en la comunidad}

\author{
PAULINA MUÑOZ ${ }^{1, \mathrm{a}}$, M. LUISA GARMENDIA², \\ MAURICIO RUIZ ${ }^{3}$, ROLANDO PIZARRO ${ }^{4}$, PATRICIO ROSSI ${ }^{5}$, \\ YARA PRADES ${ }^{1, b, c}$, LUCÍA HUENCHUR ${ }^{5}$, LUIS LIZAMA ${ }^{1, c}$, \\ SANDRA AMPUERO ${ }^{1, c, d}$, CARMEN LARRAÑAGA ${ }^{1}$, \\ L. FIDEL AVENDAÑO ${ }^{1}$, VIVIAN LUCHSINGER ${ }^{1}$
}

\section{Yield of two mortality predictors in immunocompetent patients with community acquired pneumonia}

Background: The severity of community acquired pneumonia (CAP) can be evaluated by the PSI and CURB-65 scales. However, it is unknown whether their predictive capacity varies according to the etiology of the disease. Aim: To compare the performance of these scales in adults with viral, bacterial, mixed, and no agent detected CAP. Material and Methods: We studied 725 patients hospitalized for CAP aged 18 to 95 years (47\% females) Urinary S. pneumoniae and Legionella antigens were detected by immunochromatography (Binax $\left.{ }^{\circledR}\right)$. Respiratory viruses and bacteria were detected by PCR in nasopharyngeal smears. The proportions of deaths, admission to the intensive care unit (ICU), and oxygen therapy were compared between mild and non-severe patients defined by PSI (I/II and I-III) and CURB-65 ( 1 and 1-2), according to the causative agent. Results: Ten percent of patients died. A causative agent was detected in 65\%. The proportion of mild and non-severe patients according to PSI and CURB-65, and of deceased patients, admitted to the ICU and with oxygen therapy was similar in the four categories per agent. There were no deaths among non-severe patients with bacterial CAP. However, $6 \%$ of patients with CAP caused by virus or without causative agents, died. No deaths occurred among mild patients with bacterial CAP. In viral CAP, no deaths occurred among patients classified as mild only by PSI. The yields of PSI were greater than those of CURB-65 in non-severe patients who died and were admitted to the ICU with bacterial and viral CAP (5 and 14\%; 7 and $12 \%$ respectively, $p=0.04)$. Conclusions: The prognostic performance of PSI in CAP varies according to the causative agent in adults. It is higher in non-severe bacterial cases, and superior to CURB-65.

(Rev Med Chile 2021; 149: 1275-1284)

Key words: Community-Acquired Infections; Immunocompetence; Pneumonia.

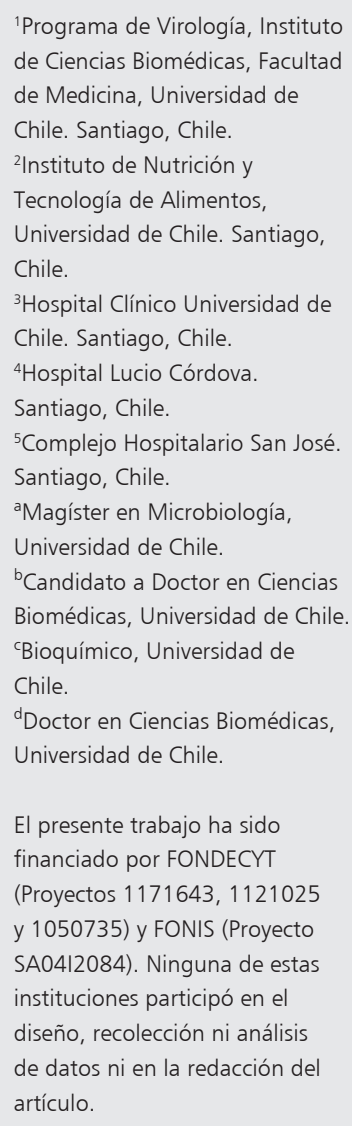

El presente trabajo ha sido financiado por FONDECYT (Proyectos 1171643, 1121025 y 1050735) y FONIS (Proyecto SA0412084). Ninguna de estas instituciones participó en el diseño, recolección ni análisis de datos ni en la redacción del artículo.

Los autores declaran no tener conflictos de interés.

Recibido el 21 de abril de 2020, aceptado el 1 de junio de 2021 .

Correspondencia a: Dra. Vivian Luchsinger $F$. Programa de Virología, ICBM, Facultad de Medicina, Universidad de Chile. Independencia 1027, Independencia. Santiago, Chile. vluchsin@uchile.cl 
L a neumonía adquirida en la comunidad (NAC) es un problema de salud pública mundial por su alta morbilidad y mortalidad, requiriendo hospitalización $20-40 \%$ de los pacientes y falleciendo 5-10\% ${ }^{1}$. En Chile, representa la tercera causa de muerte, especialmente en mayores de 65 años ( 18 casos/ 100.000 habitantes $)^{1-4}$. El agente único más frecuente es Streptococcus pneumoniae, detectándose en alrededor de un tercio de los $\operatorname{casos}^{3-8}$. Otros microorganismos se presentan con una incidencia variable y menor, e incluyen Haemophilus influenzae, Staphylococcus aureus, Chlamydia pneumoniae, Mycoplasma pneumoniae, Legionella pneumophila y Moraxella catarrhalis ${ }^{7-14}$. Los virus respiratorios se detectan en $29-55 \%$ de las NAC, y entre ellos se incluye el virus influenza, parainfluenza, virus respiratorio sincicial, adenovirus, rinovirus y metapneumovirus ${ }^{6-7}$. En el $16,9 \%$ se detecta coinfección viral y bacteriana simultánea ${ }^{3,7}$.

La NAC se presenta con calofríos, fiebre, tos con o sin esputo, dificultad para respirar y dolor torácico ${ }^{13-17}$. La presentación clínica no permite diferenciar el agente etiológico ${ }^{7,11}$. La gravedad del adulto con NAC se evalúa con escalas pronósticas que ponderan el riesgo de muerte del paciente para orientar el manejo médico. Las más conocidas son el índice de gravedad de la neumonía (PSI) y CURB-65 $5^{13,14}$. PSI fue desarrollado para identificar a pacientes con bajo riesgo de muerte, recomendando el manejo ambulatorio, y CURB-65 identifica a pacientes con riesgo de mortalidad indicando hospitalización e ingreso a $\mathrm{UCI}^{13-19}$. La aplicabilidad clínica de ambos índices predictivos es limitada porque en la práctica algunos pacientes son erróneamente clasificados.

La relación entre gravedad y agentes infecciosos en adultos con NAC no está bien dilucidada $^{6,7,19-25}$. Algunos autores no encontraron relación entre agente detectado y gravedad de la enfermedad ${ }^{7}$, otros plantean un mejor pronóstico en los casos virales ${ }^{11}$. Se desconoce si la capacidad predictiva de las escalas pronósticas varía según la etiología de la NAC. El objetivo de este estudio fue comparar el rendimiento de las escalas PSI y CURB-65 en adultos con NAC asociadas a virus, bacterias y ambos tipos de agentes.

\section{Pacientes y Método}

\section{Pacientes}

Se analizaron 725 adultos con NAC, definida por presencia de síntomas respiratorios por menos de una semana y radiografía de tórax con infiltrados pulmonares recientes ${ }^{3}$. Se excluyeron pacientes con inmunocompromiso (VIH, tratamiento inmunosupresor u oncológico, trasplante de órganos, en diálisis) y hospitalizados en los 30 días previos al enrolamiento. Los pacientes fueron enrolados en los hospitales Clínico U. de Chile, Dr. L. Córdova, Complejo hospitalario San José y en la Clínica Santa María de Santiago de Chile, entre 2012-2018. Todos aceptaron participar voluntariamente y firmaron un consentimiento informado. El Comité de Ética de Investigación en Seres Humanos de la Facultad de Medicina y del Hospital Clínico U. de Chile y el Comité Ético Científico de los Servicios de Salud Metropolitano Sur, Oriente y Norte aprobaron el estudio.

Se registraron datos demográficos, comorbilidades, cuadro clínico, parámetros de laboratorio, terapia antimicrobiana y evolución (insuficiencia respiratoria o renal, shock, ventilación mecánica y hospitalización en la unidad de cuidados intensivos (UCI)). Se registró el fallecimiento durante la hospitalización o hasta un mes pos alta hospitalaria, según fecha consignada en el Registro Civil nacional.

Para el cálculo del tamaño muestral, se estimó que con una muestra de 725 sujetos se podría mostrar hasta $7 \%$ de diferencia en la mortalidad respecto al grupo de mayor puntaje, con un poder muestral del $80 \%$, un nivel de confianza del $95 \%$ y $10 \%$ de mortalidad en el grupo de menor puntaje en escala PSI.

\section{Evaluación por escalas clínicas PSI y CURB-65}

Los pacientes fueron evaluados al ingreso y clasificados según el índice PSI y CURB-65. PSI incluye 20 variables demográficas y clínicas que estratifican a los enfermos en 5 grupos de riesgo según mortalidad y manejo: grupos I-II: leves, mortalidad $<1 \%$ se indica tratamiento ambulatorio; grupo III: moderado, mortalidad 0,9-2,8\%; graves IV y V: hospitalización e ingreso a unidades de cuidados intensivos (UCI), mortalidad 31\% (clase V) ${ }^{14-19}$. CURB-65 incluye 5 variables, sumando 1 punto por cada una pre- 
sente en el paciente: compromiso de conciencia, urea $>20 \mathrm{mg} / \mathrm{dl}$, frecuencia respiratoria $>30 /$ min, presión arterial sistólica $<90 \mathrm{~mm}$ de $\mathrm{Hg}$ o diastólica $\leq 60 \mathrm{~mm}$ de $\mathrm{Hg}$ y edad $\geq 65$ años $^{3,14-19}$. Los enfermos se clasifican en tres categorías según puntaje y riesgo: leves: $\leq 1$ punto, tratamiento ambulatorio; moderado:2 puntos, considerar hospitalización y graves: $\geq 3$ puntos, se recomienda hospitalizar ${ }^{14-19}$.

\section{Detección de agentes virales y bacterianos}

En ácidos nucleicos extraídos de aspirados y/o torulados nasofaríngeos con tiocianato de guanidinio-fenol-cloroformo o Favorprep ${ }^{\mathrm{TM}}$ Viral Nucleic Acid Extraction (Favorgen ${ }^{\circledR}$ ), se investigó virus respiratorio sincicial, adenovirus, influenza $\mathrm{A} / \mathrm{B}$, virus parainfluenza, metapneumovirus, coronavirus humano, bocavirus humano y rinovirus mediante reacción en cadena de la polimerasa en tiempo real con transcripción inversa (RT-PCR) con los kits ARVI Screen Real-TM1, Influenza A,B Real-TM1 (Sacace Biotechnologies o Argene) y/o Luminex xTAG1 Panel Viral Respiratorio FAST v2 (Luminex1 Corp., Canadá), según instrucciones del fabricante ${ }^{8}$. Se detectaron antígenos urinarios de Streptococcus pneumoniae y Legionella $s p$ mediante inmunocromatografía $\left(\right.$ Binax $\left.^{\circledR}\right)$ y se amplificó Mycoplasma pneumoniae y el segmento cromosómico (PstI 474) de Chlamydophila pneumoniae mediante reacción en cadena de la polimerasa $(\mathrm{RCP})^{7}$. En algunos pacientes se registraron hemocultivos, tinción de Gram y cultivo de esputo ${ }^{8}$.

\section{Análisis estadístico}

Se realizó un análisis descriptivo con medidas de tendencia central (promedios/medianas) y de dispersión (rangos) para las variables cuantitativas y distribución de frecuencias para las variables categóricas. El rendimiento pronóstico de cada escala se evaluó en base al porcentaje de casos leves que falleció, ingresó a UCI y requirió oxigenoterapia. Las proporciones se compararon con la prueba de Fisher en el programa Prism Graphpad y STATA 13.0. Un valor de P $<0,05$ fue considerado significativo.

Se calculó la sensibilidad, especificidad y área bajo la curva (IC95\%) de las escalas PSI y CURB65 para los tres indicadores de gravedad (mortalidad, ingreso a UCI y oxigenoterapia) según agente detectado.

\section{Resultados}

\section{Características de los pacientes}

De los 725 adultos estudiados, 26 (3,6\%) fueron ambulatorios y 700 hospitalizados $(96,4 \%)$. Las características de la población estudiada y de los agentes detectados se observa en la Tabla 1 y la distribución de los adultos con NAC según las variables incluidas en las escalas PSI y CURB-65 en la Tabla 2. Las categorías se distribuyeron en proporciones similares en los grupos con y sin detección de agente y entre los distintos tipos de agentes detectados (Tabla 4). No fue posible clasificar 66 pacientes por carencias de datos.

\section{Fallecimientos, ingresos a UCI y oxigenoterapia en adultos con NAC clasificados por PSI}

De los 701 pacientes categorizados por gravedad según PSI, 74 fallecieron: 7/22 casos virales eran moderados (18\%) y 15 graves $(36 \%)$; los 14 fallecidos con bacterias se clasificaron como graves; $2 / 11$ mixtos fallecidos eran leves $(10 \%)$ y $9(43 \%)$ graves y $2 / 27$ fallecidos sin agente eran leves (5\%), 7 moderados (12\%) y 18 graves (49\%).

Entre los enfermos leves, no hubo fallecidos en los casos bacterianos y virales, pero si en los mixtos $y$ sin agente $(\mathrm{p}>0,05)$ (Figura 1A). Entre los no graves, la proporción de fallecidos fue significativamente superior en los casos virales y sin agente que en los mixtos y bacterianos $(\mathrm{p}<0,03)$ (Figura 1B). En estos últimos no hubo fallecidos (Tabla 5).

En 119 casos fue necesaria la admisión a la UCI: $3 / 30$ casos virales eran leves (10\%), $5(13 \%)$ moderados y 22 graves (73\%); $1 / 31$ adultos con NAC bacteriana era leve (3\%), 4 moderados (13\%)y 25 graves (81\%) (un paciente sin dato); $2 / 25$ pacientes con NAC mixta eran leves $(8 \%)$, 6 moderados $(24 \%)$ y 17 graves $(68 \%)$; y $6 / 34$ enfermos sin agente detectado eran leves $(18 \%)$, 6 moderados (18\%) y 22 graves $(64 \%)$.

Aunque ningún paciente leve con NAC bacteriana ingresó a UCI, la diferencia no fue significativa respecto a los otros casos $(\mathrm{p}>0,05)$ (Figura 1A). Entre los no graves, las proporciones de casos en UCI fue similar ( $p>0,05)$ (Figura 1B) (Tabla 5).

En 297 pacientes fue necesario administrar oxígeno: 18/94 casos virales eran leves (23\%), 17 moderados (18\%) y 59 graves $(66 \%) ; 9 / 55$ con bacterias eran leves (16\%), 10 moderados (18\%) y 36 graves (61\%); 10/50 casos mixtos eran leves (20\%), 8 moderados (16\%) y 32 graves $(64 \%)$ y 
Tabla 1. Caracterización de los 725 adultos con NAC enrolados

\begin{tabular}{|c|c|c|}
\hline Características & $\mathbf{n}$ & Porcentaje \\
\hline Mediana de edad: años (rango) & $66(18-95)$ & \\
\hline Sexo Femenino/Masculino & $342 / 383$ & $47 \% / 53 \%$ \\
\hline Pacientes con oxigenoterapia & 301 & $41 \%$ \\
\hline Pacientes en UCl & 119 & $16 \%$ \\
\hline Fallecimiento & 74 & $10 \%$ \\
\hline Sin Comorbilidad & 201 & $28 \%$ \\
\hline Con Comorbilidad & 508 & $70 \%$ \\
\hline Enfermedad pulmonar obstructiva crónica (EPOC) & 166 & $33 \%$ \\
\hline Diabetes mellitus & 150 & $30 \%$ \\
\hline Hipertensión arterial & 140 & $28 \%$ \\
\hline Insuficiencia cardiaca & 125 & $25 \%$ \\
\hline Enfermedad neurológica & 86 & $17 \%$ \\
\hline Daño hepático crónico & 56 & $11 \%$ \\
\hline Asma & 46 & $9 \%$ \\
\hline Insuficiencia renal & 42 & $8 \%$ \\
\hline Neoplasia & 36 & $7 \%$ \\
\hline Sin agente detectado & 252 & $35 \%$ \\
\hline Con agente detectado & 473 & $65 \%$ \\
\hline NAC viral & 214 & $45 \%$ \\
\hline NAC bacteriana & 142 & $30 \%$ \\
\hline NAC mixta & 117 & $25 \%$ \\
\hline Rinovirus & 76 & $36 \%$ \\
\hline Influenza & 64 & $30 \%$ \\
\hline Virus Respiratorio Sincicial & 34 & $16 \%$ \\
\hline Streptococcus pneumoniae & 68 & $48 \%$ \\
\hline Mycoplasma pneumoniae & 23 & $16 \%$ \\
\hline Chlamydia pneumoniae & 19 & $13 \%$ \\
\hline Rinovirus - Streptococcus pneumoniae & 32 & $19 \%$ \\
\hline Virus Respiratorio Sincicial - Streptococcus pneumoniae & 15 & $13 \%$ \\
\hline Influenza - Streptococcus pneumoniae & 14 & $12 \%$ \\
\hline Metapneumovirus Humano - Streptococcus pneumoniae & 13 & $11 \%$ \\
\hline
\end{tabular}

2/98 pacientes sin agente eran leves (22\%), 20 moderados $(20 \%)$ y 56 graves $(57 \%)$.

Los porcentajes de pacientes que requirieron oxigenoterapia entre los casos leves (Figura 1A) y no graves (Figura 1B) fueron similares en las cuatro categorías según detección del agente (Tabla 4) $(\mathrm{p}>0,05)$.

El AUC de PSI fue mayor en los casos bacterianos que en los virales, mixtos y sin agente respecto a mortalidad, ingreso a UCI y oxigenoterapia (Tabla 6).

Fallecimientos, ingresos a UCI y oxigenoterapia en adultos con NAC según gravedad definida por CURB-65

La categorización por gravedad fue posible en 659 pacientes, 74 de los cuales fallecieron. Tres/22 casos con sólo virus eran leves (14\%), 
Tabla 2. Distribución de los adultos con NAC estudiados según las variables incluidas en las escalas PSI y CURB-65

\begin{tabular}{|lcc|}
\hline Parámetro & $\mathbf{n}$ & $\%$ \\
\hline Edad $\geq 65$ años & 382 & $57 \%$ \\
\hline Presión Diastólica $\leq 60 \mathrm{mmHg}$ & 196 & $27 \%$ \\
\hline Compromiso de Conciencia & 165 & $23 \%$ \\
\hline BUN $>30 \mathrm{mg} / \mathrm{dL}$ & 155 & $21 \%$ \\
\hline SaO2 $<90 \%$ & 149 & $21 \%$ \\
\hline Derrame pleural & 136 & $19 \%$ \\
\hline Frecuencia respiratoria $\geq 30$ resp/min & 89 & $13 \%$ \\
\hline pH $<7,35$ & 71 & $10 \%$ \\
\hline Sodio plasmático $<130 \mathrm{mEq} / \mathrm{L}$ & 71 & $10 \%$ \\
\hline Frecuencia cardiaca $\geq 125$ latidos/min & 61 & $8 \%$ \\
\hline Glicemia $\geq 250 \mathrm{mg} / \mathrm{dL}$ & 55 & $8 \%$ \\
\hline Presión arterial sistólica $<90 \mathrm{mmHg}$ & 48 & $6 \%$ \\
\hline Hematocrito $<30 \%$ & 46 & $6 \%$ \\
\hline
\end{tabular}

4 moderados (18\%) y 15 graves $(68 \%) ; 5 / 14$ con sólo bacterias eran moderados $(36 \%)$ y 9 graves (64\%); $3 / 11$ casos mixtos eran leves (27\%), 3 moderados $(27 \%)$ y 5 graves $(46 \%)$ y $4 / 26$ sin agente detectado eran leves (15\%), 6 moderados (23\%) y 16 graves $(62 \%)$.

Ningún enfermo clasificado como leve con NAC bacteriana falleció, lo que no fue significativamente menor que los fallecidos en las otras categorías $(\mathrm{p}>0,05)$ (Figura 2A). Entre los no graves, la proporción de muertes fue similar en todos los grupos de agentes $(\mathrm{p}<0,03)$ (Figura 2B) (Tabla 5).

La hospitalización en UCI fue requerida por 119 enfermos: 29 eran virales (6 leves $(21 \%), 13$ moderados $(45 \%)$ y 10 graves $(74 \%) ; 29$ bacterianos ( 3 leves $(10 \%)$, 9 moderados $(31 \%)$ y 17 graves (59\%)); 25 mixtos (4 leves (16\%), 11 moderados $(44 \%)$ y 10 graves $(40 \%)$ ) y 34 sin agente (9 leves $(27 \%), 9$ moderados $(27 \%)$ y 16 graves $(47 \%))$.

En los casos leves y en los no graves, la proporción de enfermos que ingresó a UCI fue similar en las 4 categorías definidas por la detección de agente $(\mathrm{p}>0,05)$ (Figura 2A y 2B).

Tabla 3. Características clínicas de adultos con NAC viral, bacteriana y mixta

\begin{tabular}{|lcccc|}
\hline Parámetro & $\begin{array}{c}\text { NAC viral } \\
\text { Mediana (rango) }\end{array}$ & $\begin{array}{c}\text { NAC bacteriana } \\
\text { Mediana (rango) }\end{array}$ & $\begin{array}{c}\text { NAC mixta } \\
\text { Mediana (rango) }\end{array}$ & $\begin{array}{c}\text { NAC sin agente } \\
\text { Mediana (rango) }\end{array}$ \\
\hline Estado mental alterado $\mathrm{n}(\%)$ & $58(27 \%)$ & $33(23 \%)$ & $28(24 \%)$ & $46(18 \%)$ \\
\hline Edad & $68(18-94)$ & $63(18-94)$ & $65(18-92)$ & $66(18-95)$ \\
\hline Frecuencia respiratoria resp/min & $22(12-58)$ & $22(16-48)$ & $23(15-48)$ & $22(13-46)$ \\
\hline Presión arterial sistólica mmHg & $129(67-213)$ & $120(66-198)$ & $116(56-196)$ & $124(60-253)$ \\
\hline Presion arterial diastólica mmHg & $71(35-139)$ & $70(26-101)$ & $64(31-109)$ & $69(30-123)$ \\
\hline Temperatura ${ }^{\circ} \mathrm{C}$ & $36,6(35,6-40,0)$ & $37,2(35,2-41,0)$ & $36,7(35,0-40,1)$ & $37,0(35,0-40,5)$ \\
\hline Frecuencia cardiaca latidos/min & $90(38-164)$ & $95,5(17-153)$ & $100(60-153)$ & $93(48-180)$ \\
\hline pH & $7,41(7,13-7,59)$ & $7,42(7,05-7,54)$ & $7,42(7,11-7,53)$ & $7,42(6,94-7,60)$ \\
\hline BUN mg/dL & $19,3(6,0-148,0)$ & $22(5-133)$ & $23,5(7,0-94,0)$ & $18,0(3,0-116,0)$ \\
\hline Sodio plasmático mEq/L & $137(111-198)$ & $136(115-169)$ & $136(119-149)$ & $137(121-150)$ \\
\hline Glicemia mg/dL & $132(22-460)$ & $116(50-381)$ & $123(40-480)$ & $120(50-546)$ \\
\hline Hematocrito \% & $39,0(14,5-54,0)$ & $38,0(23,0-57,8)$ & $38,0(25,2-54,0)$ & $38,0(22,1-59,0)$ \\
\hline SaO2 \% & $93(47,0-105,0)$ & $94(68-99)$ & $93,1(40,0-100,0)$ & $94,0(58,0-99,3)$ \\
\hline
\end{tabular}




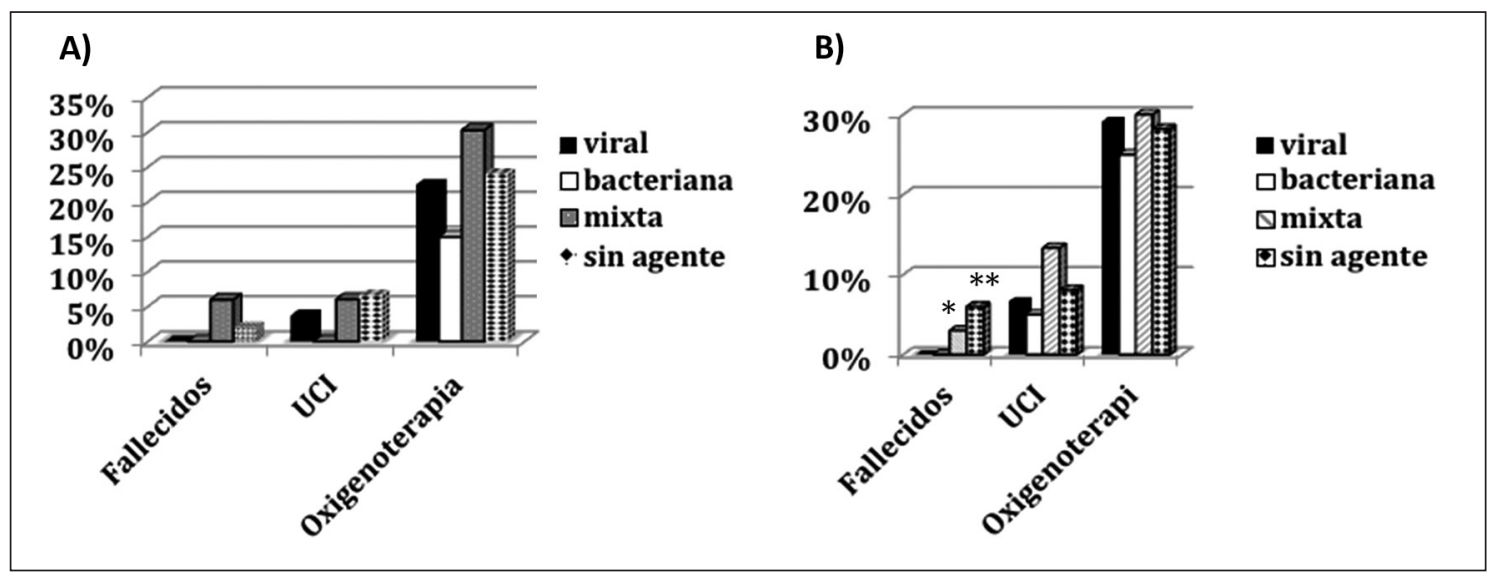

Figura 1. Porcentaje de fallecidos, ingresados a UCI o con oxigenoterapia por agente detectado en los 264 adultos con NAC leve (A) y en 413 adultos con NAC no grave según PSI (B). Prueba de Fisher; $p>0,05$, excepto: fallecidos: $p_{\text {vira/bact }}=0,04^{*}$ y $\mathrm{p}_{\text {bact/sin agente }}=0,0001^{* *}$ en los no graves.

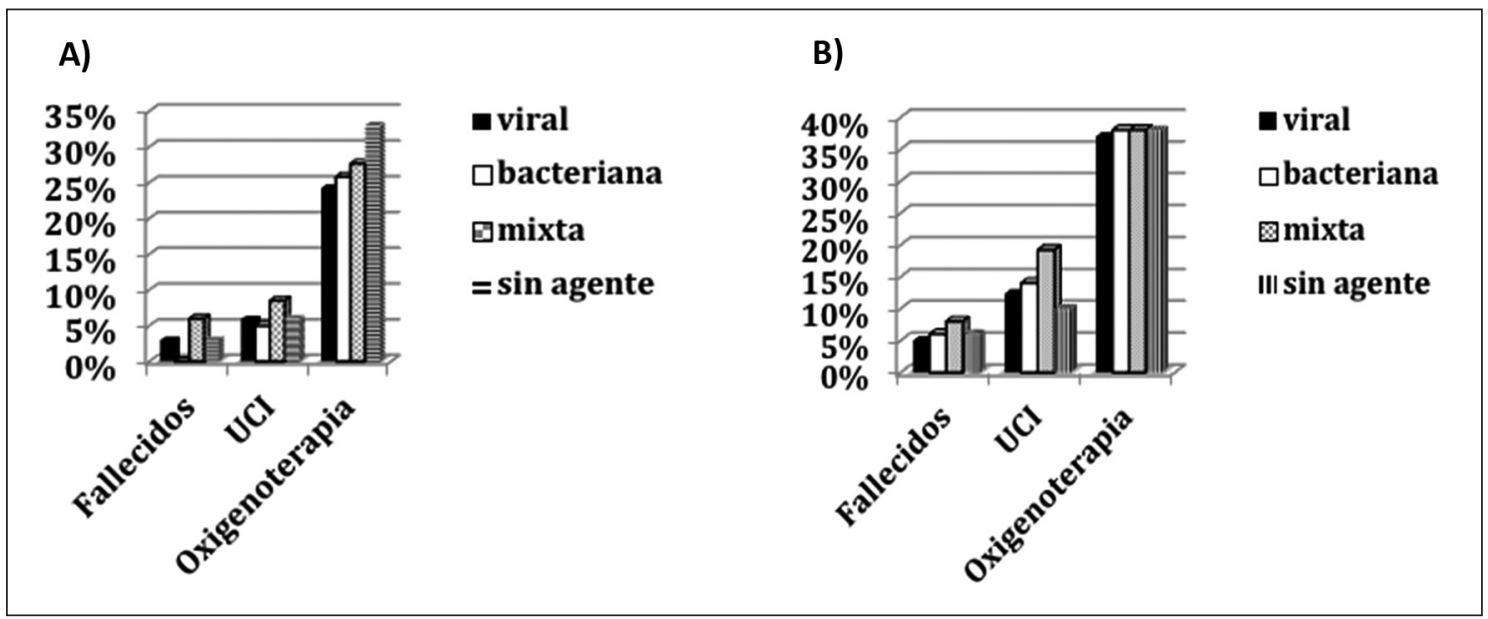

Figura 2. Porcentaje de fallecidos, ingresados a UCl o con oxigenoterapia por agente detectado en adultos con NAC leve (A) o no graves (B) según CURB-65. Prueba de Fisher; $p>0,05$.

De los pacientes que recibieron oxigenoterapia, 95 eran virales (24 leves (26\%), 33 moderados (36\%) y 35 graves (38\%); 3 pacientes sin dato); 56 bacterianos (16 leves (29\%), 17 moderados (31\%) y 22 graves (40\%); uno sin dato); 50 mixtos (13 leves (27\%), 17 moderados (35\%) y 19 graves (39\%); uno sin dato) y 98 sin agente (46 leves (47\%), 23 moderados (22\%) y 29 graves (30\%)).

En los pacientes leves y en los no graves, la proporción de casos que requirió oxigeno fue similar entre los casos virales, bacterianos, mixtos $y$ sin agente $(\mathrm{p}>0,05)$ (Figura $2 \mathrm{~A}$ y $2 \mathrm{~B})$.
El AUC de CURB-65 fue mayor en los casos bacterianos que en los virales, mixtos y sin agente, pero sólo respecto a ingreso a UCI; mayor en los casos virales respecto a oxigenoterapia e igual entre los casos bacterianos, virales y mixtos respecto a mortalidad (Tabla 6).

\section{Comparación de las escalas PSI y CURB-65}

El rendimiento de CURB-65 en los casos leves respecto a PSI fue significativamente mayor en el ingreso a UCI y oxigenoterapia, pero sólo entre los pacientes sin agente detectado (Tabla 
4). La proporción de fallecidos fue significativamente superior en los no graves definidos por CURB-65 respecto a los por PSI entre los casos bacterianos; también la de admitidos a UCI en los grupos virales y bacterianos y la de pacientes con oxigenoterapia en los virales, mixtos y sin agente (Tabla 5).
El AUC de PSI de los 3 parámetros de gravedad (mortalidad, ingreso a UCI y oxigenoterapia) fue superior al de CURB-65 en los casos bacterianos, y sólo en mortalidad y oxigenoterapia en los mixtos. CURB-65 fue superior en mortalidad y oxigenoterapia en los casos virales y en mortalidad e ingreso a UCI en los sin agente (Tabla 6).

Tabla 4. Categorización por gravedad según PSI y CURB-65 de los adultos con NAC viral, bacteriana, mixta y sin agente estudiados

\begin{tabular}{|c|c|c|c|c|c|c|c|c|}
\hline & \multicolumn{2}{|c|}{ n total } & \multicolumn{2}{|c|}{ Leve } & \multicolumn{2}{|c|}{ Moderado } & \multicolumn{2}{|c|}{ Grave } \\
\hline & PSI & CURB-65 & PSI & CURB-65 & PSI & CURB-65 & PSI & CURB-65 \\
\hline Total n (\%) & 701 (100) & $659(100)$ & $263(38)$ & $351 \quad$ (53) & $143(20)$ & $151(23)$ & $295(42)$ & $153(23)$ \\
\hline Virus & $210 \quad(30)$ & $198 \quad(30)$ & $80(30)$ & 102 (29) & $40(28)$ & $52(34)$ & $90(31)$ & $40(26)$ \\
\hline Bacteria & 136 (19) & 127 (19) & $59(23)$ & $61 \quad(17)$ & 18 (13) & 28 (19) & $59(20)$ & $38(24)$ \\
\hline Mixto & 110 (16) & 105 (16) & $33(13)$ & $47 *(13)$ & 27 (19) & $31(21)$ & $50(17)$ & $27(18)$ \\
\hline Sin agente & $245 \quad$ (35) & $229 \quad(35)$ & $91(34)$ & $141(40)$ & $58(41)$ & $40(26)$ & $96(33)$ & $48(31)$ \\
\hline
\end{tabular}

Leve: grupos I-II de PSI y 1 de CURB-65. Moderado: grupo III de PSI y 2 de CURB-65. Grave: grupos IV-V de PSI y 3 de CURB-65. La proporción de casos según gravedad definidos por PSI y CURB-65 fue similar entre las cuatro categorías por agente $p>0,05$, *excepto los casos leves clasificados por CURB-65 entre NAC mixta y sin agente ( $p=0,004)$, mediante prueba de Fisher.

Tabla 5. Resumen comparativo de las proporciones de fallecidos, ingresados a UCl o con oxigenoterapia entre adultos con NAC viral, bacteriana y mixta leves o no graves de a la clasificación por PSI y CURB-65

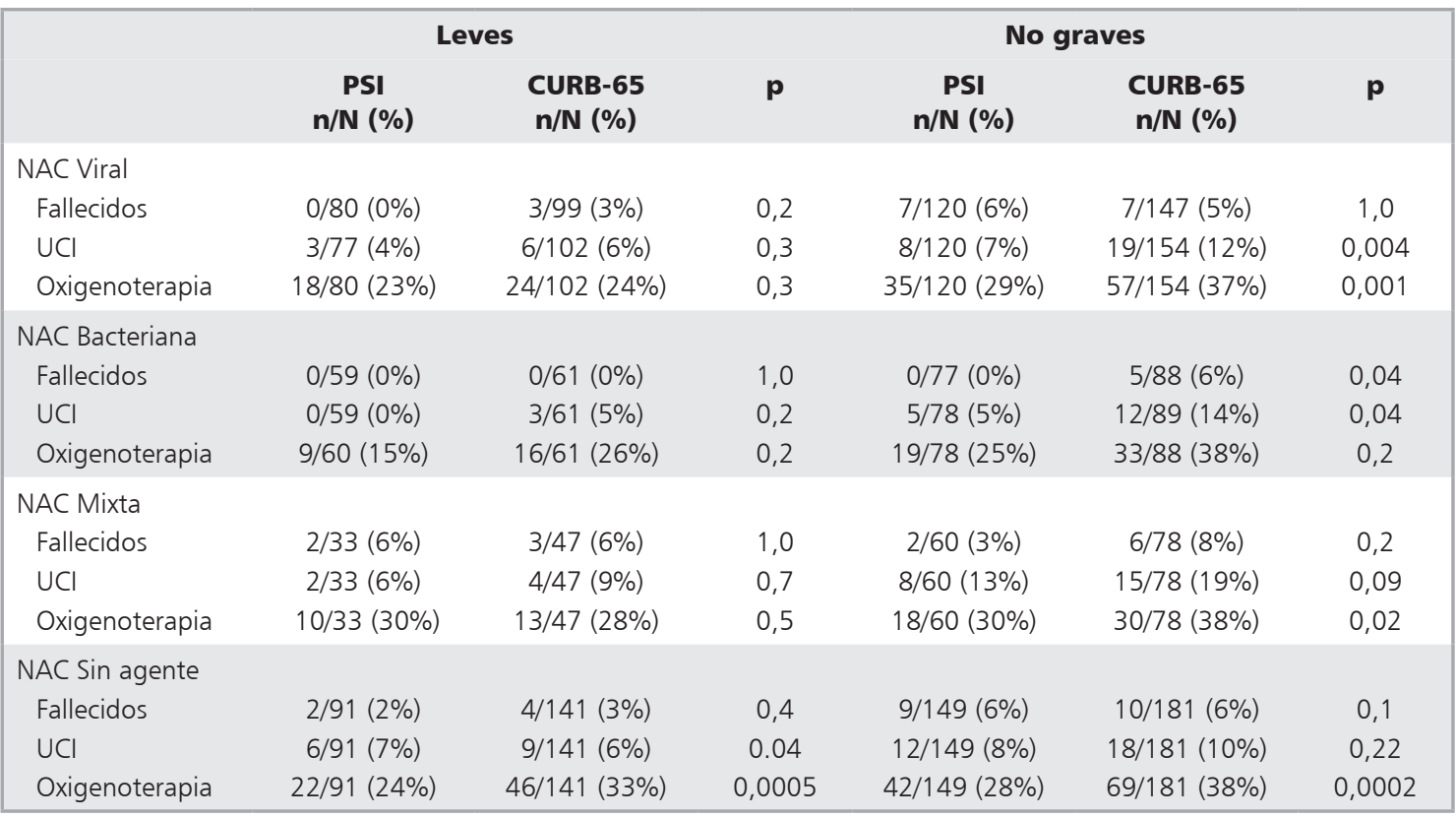

Leves: grupos I-II de PSI y 1 de CURB-65. No graves: grupos I- III de PSI y 1-2 de CURB-65. UCI: unidad de cuidados intensivos. Valores de $\mathrm{p}$ obtenidos con prueba de Fisher. 
Tabla 6. Área bajo la curva ROC de las escalas PSI y CURB-65 según parámetros de gravedad y agente detectado en adultos con NAC

\begin{tabular}{|lcccccc|}
\hline & \multicolumn{2}{c}{$\begin{array}{c}\text { Mortalidad } \\
\text { AUC } \\
\text { (IC95\%) }\end{array}$} & \multicolumn{2}{c}{$\begin{array}{c}\text { Ingreso a UCI } \\
\text { AUC } \\
\text { (IC95\%) }\end{array}$} & \multicolumn{2}{c|}{$\begin{array}{c}\text { Oxigenoterapia } \\
\text { AUC } \\
\text { (IC95\%) }\end{array}$} \\
& PSI & CURB-65 & PSI & CURB-65 & PSI & CURB-65 \\
Total & 0,76 & 0,77 & 0,72 & 0,72 & 0,72 & 0,68 \\
& $(0,71-0,81)$ & $(0,72-0,82)$ & $(0,70-0,79)$ & $(0,67-0,76)$ & $(0,69-0,76)$ & $(0,64-0,72)$ \\
Viral & 0,74 & 0,79 & 0,72 & 0,67 & 0,74 & 0,75 \\
& $(0,65-0,82)$ & $(0,69-0,89)$ & $(0,64-, 81)$ & $(0,58-0,76)$ & $(0,68-0,81)$ & $(0,69-0,81)$ \\
Bacteriana & 0,84 & 0,79 & 0,88 & 0,76 & 0,77 & 0,66 \\
& $(0,77-0,91)$ & $(0,71-0,87)$ & $(0,82-0,94)$ & $(0,68-0,85)$ & $(0,69-0,85)$ & $(0,57-0,75)$ \\
Mixta & 0,74 & 0,63 & 0,69 & 0,69 & 0,70 & 0,69 \\
& $(0,54-0,94)$ & $(0,46-0,81)$ & $(0,59-0,80)$ & $(0,58-0,79)$ & $(0,61-0,80)$ & $(0,59-0,78)$ \\
Sin agente & 0,74 & 0,79 & 0,69 & 0,72 & 0,69 & 0,63 \\
& $(0,65-0,83)$ & $(0,71-0,88)$ & $(0,59-0,79)$ & $(0,65-0,81)$ & $(0,62-0,75)$ & $(0,56-0,69)$ \\
\hline
\end{tabular}

AUC: área bajo la curva. IC95\%: intervalo de confianza al 95\%.

\section{Discusión}

El rendimiento de PSI y CURB-65 respecto a mortalidad fue óptimo y superior en los adultos con NAC bacterianas, dado que ningún caso leve falleció demostrando una correcta clasificación. Lo mismo ocurre con PSI en los enfermos no graves bacterianos. Esto podría deberse al mejor manejo médico de los casos bacterianos, puesto que todo paciente con neumonía recibe antibióticos para disminuir el riesgo de evolución a gravedad ${ }^{3,10,25,26}$. Por el contrario, en las NAC virales, sólo se dispone de terapia antiviral específica en los casos con influenza.

Es esencial el parámetro de gravedad que se utiliza para evaluar la eficacia pronóstica de estas escalas, siendo recomendable aplicar el número de fallecidos por ser el más objetivo. Así, el mayor rendimiento de PSI y CURB-65 en las NAC bacterianas que virales y mixtas considerando la mortalidad, no se detectó respecto al ingreso a UCI o a oxigenoterapia. Esto es congruente con el propósito para el cual fueron diseñadas estas escalas.

PSI mostró un rendimiento superior a CURB65 en los casos bacterianos, con mayor AUC en los 3 parámetros de gravedad analizados. Este comportamiento no fue similar en las otras categorías de agentes, lo que concuerda con lo publicado por Shehata y cols. ${ }^{26}$. En ingreso a UCI y oxige- noterapia, pero no en mortalidad, PSI también fue superior en las virales y mixtas. Por todo lo anterior, podría ser necesario evaluar la escala a aplicar según el agente detectado.

En los casos leves, el rendimiento fue similar para ambas escalas, pero no en los no graves. Es posible que la inclusión de los casos moderados en este último grupo contribuya a las diferencias, comportándose como graves y no como leves en cualquier tipo de agente detectado.

La inclusión mayoritaria de hospitalizados podría ser un sesgo del estudio, pero el alto porcentaje de pacientes clasificados como leves por ambas escalas permite realizar los análisis apropiadamente. Diversas son las causas que explican la hospitalización de casos leves, incluyendo factores sociales como la carencia de red de apoyo al paciente, la subvaloración de la gravedad de algunos pacientes debido a las escalas aplicadas (disminución de puntaje por ser mujer y joven en PSI o la no inclusión de comorbilidades descompensada en CURB-65) y, con frecuencia, por la no aplicación de criterios objetivos de gravedad para decidir la hospitalización, lo cual refuerza la necesidad de evaluar la utilidad clínica de estas escalas.

Si bien la mejor muestra para la búsqueda del agente etiológico en una neumonía sería la del tracto respiratorio inferior, su obtención requiere de procedimientos invasivos que se restringen a determinados pacientes por su condición médica. 
Esta limitante del estudio está compensada parcialmente con la utilización de técnicas de alta sensibilidad, como la RCP que permite ampliar la detección de agentes infecciosos, y la detección de antígeno urinario de $S$. pneumoniae. El alto rendimiento de esta última técnica, aún con la administración previa de antibiótico ${ }^{27}$, en la detección del agente bacteriano más frecuente en los adultos con $\mathrm{NAC}^{7,11}$, reduce la proporción de casos bacterianos no detectados.

En conclusión, el rendimiento pronóstico de PSI respecto a mortalidad varía según el agente de la NAC en adultos, siendo superior en adultos con NAC bacteriana. El rendimiento pronóstico de PSI es superior a la de CURB-65, especialmente en los casos bacterianos no graves.

Agradecimientos: Agradecemos al personal de enfermería y kinesiología de los hospitales por la obtención de las muestras y a Cristian Moreno por su excelente apoyo técnico en el laboratorio.

\section{Referencias}

1. Sociedad Chilena de Enfermedades Respiratorias y Sociedad Chilena de Infectología. Consenso Nacional 2005: Manejo de la neumonía del adulto adquirida en la comunidad. Rev Chil Enf Respir 2005; 21: 69-140.

2. Valdivia G. Epidemiología de la neumonía del adulto adquirida en la comunidad. Rev Chilena Infectol 2005; 22: 11-7.

3. Ministerio de Salud de Chile. Guía Clínica AUGE: Neumonía adquirida en la comunidad en adultos de 65 años y más. Manejo ambulatorio. Guías clínicas Minsal Chile 2011; 1: 25. http://www.bibliotecaminsal.cl/wp/ wp-content/uploads/2016/04/Neumonia-Adquiridaadultos-de-65-años-y-más.pdf.

4. Martín AA, Moreno-Pérez D, Alfayate S, Couceiro JA, García ML, Korta J, et al. Etiología y diagnóstico de la neumonía adquirida en la comunidad y sus formas complicadas. An Pediatr España 2011; 76 (3): 162e1$162 \mathrm{e} 18$

5. Wang K, Xi W, Yang D, Zheng Y, Zhang Y, Chen Y, et al. Rhinovirus is associated with severe adult community-acquired pneumonia in China. J Thorac Dis 2017; 9 (11):4502-11.

6. Musher D, Abers M, Bartlett J. Evolving Understanding of the Causes of Pneumonia in Adults, With Special Attention to the Role of Pneumococcus. Clinical Infectious Diseases 2017:65(10): 1731-44.
7. Luchsinger V, Ruiz M, Zunino E, Martínez M, Machado C, Piedra $\mathrm{P}$, et al.Community-acquired pneumonia in Chile: The clinical relevance in the detection of viruses and atypical bacteria. Thorax 2013; 68 (11): 1000-6.

8. Prina E, Ranzani O, Torres A. Community-acquired pneumonia. Lancet Respir Med 2015; 386 (9998): 1097 108.

9. Díaz A, Fuentes G, Couble B, Uribe R, Mercado G, Soza A, et al. Etiología de la neumonía adquirida en la comunidad en adultos hospitalizados en Santiago, Chile: implicancias para las guías clínicas. Rev Chil Enf Respir 2005; 21: 23 (1)-32.

10. Riquelme R, Riquelme M, Rioseco M, Gómez V, Gil R, Torres A. Etiología y factores pronósticos de la neumonía adquirida en la comunidad en el adulto hospitalizado, Puerto Montt, Chile. Rev Med Chile 2006; 134 (5): 597-605.

11. Saldías F, Gassmann J, Canelo J, Díaz O. Características clínicas de la neumonía adquirida en la comunidad del adulto inmunocompetente hospitalizado según el agente causal. Rev Med Chile 2018; 146 (12): 1371-83.

12. Torres A, Barberán J, Falguera M, Menéndez R, Molina J, Olaechea P, et al. Guía multidisciplinar para la valoración pronóstica, diagnóstico y tratamiento de la neumonía adquirida en la comunidad. Med Clin Barc. 2013; 140 (5): 223e1- 223e19.

13. Agüero A, Rivera S, Salas F. Abordaje actualizado sobre la neumonía adquirida en la comunidad en adultos. Rev Ciencia \& Salud 2020; 4 (3): 54-64.

14. Bantar C, Curcio D, Jasovich A, Bagnulo H, Arango A, Bavestrello L, et al. Neumonía aguda adquirida en la comunidad en adultos: Actualización de los lineamientos para el tratamiento antimicrobiano inicial basado en la evidencia local del Grupo de Trabajo de Sudamérica (ConsenSur II). Rev. Chil. infectol. 2010; 27 (Supl 1): 9-38.

15. Lim WS, Van der Eerden MM, Laing R, Boersma WG, Karalus N, Town GI, et al. Defining community-acquiredpneumonia severity on presentation to hospital: an international derivation and validation study. Thorax. 2003; 58 (5): 377-82.

16. Ewig S, de Roux A, Bauer T, García E, Mensa J, Niederman $\mathrm{M}$, et al. Validation of predictive rules and indices of severity for community acquired pneumonia. Thorax 2004; 59 (5): 421-7.

17. Fine MJ, Auble TE, Yealy DM. A prediction rule to identify low-risk patients with community-acquired pneumonia. N Engl J Med. 1997; 336 (4): 243-50.

18. Saldías F, Farías G, Villarroel L, Valdivia C, Mardónez J, Díaz A. Diseño de un índice pronóstico clínico para 
el manejo de la neumonía del adulto adquirida en la comunidad. Rev Med Chile 2004; 132 (9): 1037-46.

19. Capelastegui A, España P, Quintana JM, Areitio I, Gorordo I, Egurrola M, et al. Validation of a predictive rule for the management of community-acquired pneumonia. Eur Respir J. 2006; 27 (1): 151157.

20. Madhu S, Augustine S, Kumar Y, Kauser M, Kumar S, Jayaraju B. Comparative study of CURB-65, Pneumonia Severity Index and IDSA/ATS scoring systems in community acquired pneumonia in an Indian tertiary care setting. Int J Adv Med. 2017; 4: 693.

21. Bermejo-Martin JF, Almansa R, Martin-Fernández M, Menendez R, Torres A. Immunological profiling to assess disease severity and prognosis in community-acquired pneumonia. Lancet Respir Med 2017; 5 (12): e35-e36.

22. Voiriot G, Visseaux B, Cohen J, Nguyen L, Neuville M, Morbieu C, et al. Viral-bacterial coinfection affects the presentation and alters the prognosis of severe community-acquired pneumonia. Critical Care 2016; (1): 20:375.

23. Cillóniz C, Ewig S, Polverino E, Marcos M, Esquinas C,
Gabarrús A, et al. Microbial aetiology of community-acquired pneumonia and its relation to severity. Thorax 2011; 66 (4): 340-6.

24. Méndez R, Torres A, Aspa J, Capelastegui A, Prat C, Rodrígues de castro F. Neumonía adquirida en la comunidad. Nueva normativa de la Sociedad Española de Neumología y Cirugía Torácica (SEPAR). Arch Bronconeumol. 2010; 46 (10): 543-58.

25. Alimi Y, Lim WS, Lansbury L, Leonardi-Bee J, Nguyen-Van-Tam JS. Systematic review of respiratory viral pathogens identified in adults with community-acquired pneumonia in Europe. J Clinical Virology 2017; 95:2635.

26. Shehata M, Sileem A, Shahien N. Prognostic values of pneumonia severity index, CURB-65 and expanded CURB-65 scores in community-acquired pneumonia in Zagazig University Hospitals. Egypt. J Chest Dis Tuberc. 2017; 66: 549-55.

27. Weatherall C, Paoloni R, Gottlieb T. Point-of-care urinary pneumococcal antigen test in the emergency Department for commuity acquired pneumonia. Emerg Med J 2008; 25 (3): 144-8. 